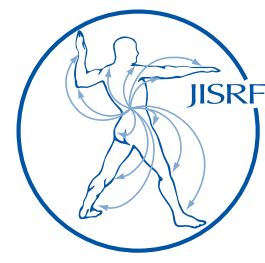

\title{
Bone Preservation in a Novel Patient Specific Total Knee Replacement
}

\author{
Kurtz $W^{1}$, Slamin $J^{2}$, Doody $S^{2}$
}

\section{Abstract}

Background: The volume of total knee arthroplasty procedures is growing rapidly and, correspondingly, it is expected that the volume of revision procedures will grow rapidly as well. Revision surgery is most successful when adequate bone remains on both the tibia and femur to allow for the least invasive revision.

We hypothesized that total knee arthroplasty with a patient-specific implant would result in significant bone preservation as compared to standard total knee arthroplasty with "off-the-shelf" implants.

Methods: We evaluated 100 total knee arthroplasties which utilized patient-specific implants, versus 37 standard posterior stabilized and 32 standard posterior cruciate retaining total knee arthroplasties. Bone resection was quantified utilizing intra-operative measurements of actual resected bone. Additionally we performed a virtual, CAD-based analysis of resections via CT imaging on 15 knees.

Findings: We found that patients had significantly less bone resected in all zones measured, on both the femur and tibia, when patient-specific implants with patient-specific jigs were used. When assessed volumetrically with CAD imaging, standard implants resected $12-49 \%$ more bone than did patient-specific implants, depending on the size of the implant utilized.

Interpretations: Utilizing patient-specific implants in total knee arthroplasty results in significant bone sparing as compared to standard total knee arthroplasty. This has the potential for less invasive revision surgery in the future, possibly obviating the need for dedicated revision implants or augments and other bone substituting devices.

Keywords: total knee arthroplasty, bone resection, bone preservation, patient-specific implant Level of Evidence: AAOS Therapeutic Level II

\section{Introduction}

In 2013 approximately 800,000 knee replacement surgeries were conducted, including partial knee, primary total knee, and revision knee surgeries. Kurtz et al. have predicted that revision knee surgeries will grow to over 250,000 procedures by 2030 [1].

Because of the anticipated increase in revision surgeries in the future, it is important to be mindful of the poten-
1 William. B. Kurtz, MD

Tennessee Orthopedic Alliance, 301 21st Ave N, Nashville, TN 37203 USA 2. John E. Slamin; Scott W. Doody

ConforMIS Inc., 28 Crosby Dr, Bedford, MA 01730 USA

(Direct reprint requests to John E. Slamin)

(C) 2016 Kurtz, Slamin, Doody. All rights reserved.

Authors retain copyright and grant the journal right of first publication with the work. Reconstructive Review follows the Creative Commons Attribution-NonCommercial CC BY-NC. This license allows anyone to download works, build upon the material, and share them with others for non-commercial purposes as long as they credit the senior author, Reconstructive Review, and the Joint Implant Surgery \& Research Foundation (JISRF). An example credit would be: "Courtesy of (senior author's name), Reconstructive Review, JISRF, Chagrin Falls, Ohio". 
tial for a revision during the performance of the primary surgery. Maximizing bone preservation during a primary knee replacement is especially important as substantial bone loss during a subsequent revision surgery can complicate surgical techniques and compromise outcomes of the revision.

A typical primary total knee femoral component has distal condylar thicknesses that range between $8.5 \mathrm{~mm}$ and $10 \mathrm{~mm}$. Posterior condylar thicknesses can range from $8 \mathrm{~mm}$ to $11 \mathrm{~mm}$ in standard flexion implant systems. The 'high flexion' femoral components can have posterior condyles that are as thick as $13 \mathrm{~mm}$. The thickness of the implant correlates directly to the amount of bone resection that is required to implant the prosthesis, as most implant systems attempt to restore the amount of bone that is removed as closely as possible.

It remains unknown if, as is seen with hip resurfacing, bone preservation leads to improved proprioception [2]. It is clear that improved bone preservation means less chance for dramatically altering the articular surface geometry.

In this study, we hypothesized that a total knee replacement (TKR) system with a patient-specific design would result in substantial preservation of bone compared to a standard off the shelf implant system. This in turn would preserve more native bone in the event of a revision.

\section{Patient-Specific Total Knee Replacement Design Concept}

Designing a TKR that will fit the patient's geometry requires detailed information on the patient's bone that can only be provided by computed tomography (CT) scanning or other 3D imaging scans. Utilizing proprietary software, the CT data, required to manufacture an iTotal ${ }^{\circledR}($ ConforMIS, Bedford, MA) patient-specific implant, is post processed and converted into a computer assisted design(CAD) solid model. A secondary proprietary software system is then used to analyze the bone geometry and design the femoral component. Predefined design rules that are embedded into the software are applied in the design process. The predefined design rules include the coronal radii for the trochlear groove and condyles, which are designed with low polyethylene wear in mind, employing radii that have been shown to produce low contact stress [3]. The embedded design rules include recreation of the patient's natural sagittal 'J' curves for the medial condyle, the trochlear groove, and the lateral condyle.

This patient-specific implant design requires thinner cross sections of the component, which should require less bone removal in the implantation procedure. Traditional TKR femoral components employ a multifaceted bone side geometry. Typical thicknesses for these components can be $9 \mathrm{~mm}$ for the distal condyles and $8 \mathrm{~mm}$ for the posterior condyles. Contemporary femoral components have 5 facets: the anterior flange, the anterior chamfer, the distal surface, the posterior chamfer, and the posterior condyle surface. All of these surfaces are coplanar between the medial and lateral condyles on the traditional TKR.

In the iTotal, each facet is placed where maximum bone preservation can be achieved while still maintaining adequate fatigue strength. Furthermore, the iTotal employs six facets rather than the traditional 5 faceted cuts. The rationale for choosing six bone cuts, and their thickness, was determined based on the results of finite element modeling and subsequent fatigue testing. There are also embedded design rules within the proprietary software that control the thickness of the femoral component. This 6-cut design concept has been shown to provide adequate fatigue strength and, for the same component thickness, to be stronger than a 5-cut design [4].

Frequently, a patient's femur, when viewed in the coronal plane, displays an asymmetry between the lateral and medial condyles. This natural condylar offset is defined as the coronal offset. The iTotal femoral component respects these patient specific differences and is designed with the patient's exact coronal offset. The coronal offset is defined as the height difference between the medial and lateral femoral condyles as viewed in the coronal extension plane. This typically creates an asymmetry of the extension gap that must be accounted for at the tibial articular surface, much in the same manner that the natural human knee does. The same is true for the posterior condyles of the femur. Typically, the lateral posterior condyle is shorter than the medial condyle creating a unique asymmetry in the flexion space as well. These are the patient-specific design elements along with the patient's unique 'J' curvatures that are incorporated into the femoral component of the iTotal Cruciate Retaining Knee System. Figure 1 shows a typical post processed bone model in CAD with the pre-

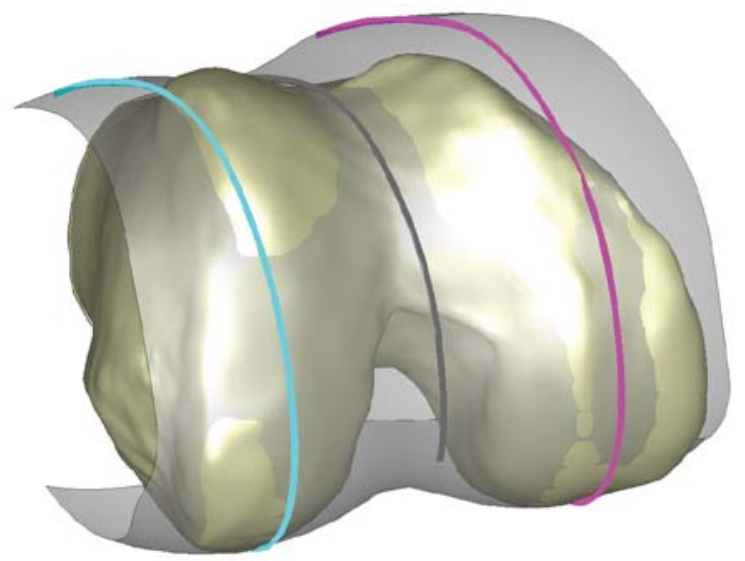

Figure 1. Showing in process stage of patient-specific 'J' curves on a $C A D$ model of the distal femur. 
liminary patient specific ' $J$ ' curves in the early stages of design within the proprietary implant software program. Figure 2 shows a typical iTotal complete implant system. The patient-specific condylar widths and asymmetry, the trochlear shape, coronal center to center, and the distal offset are clearly evident in this image.

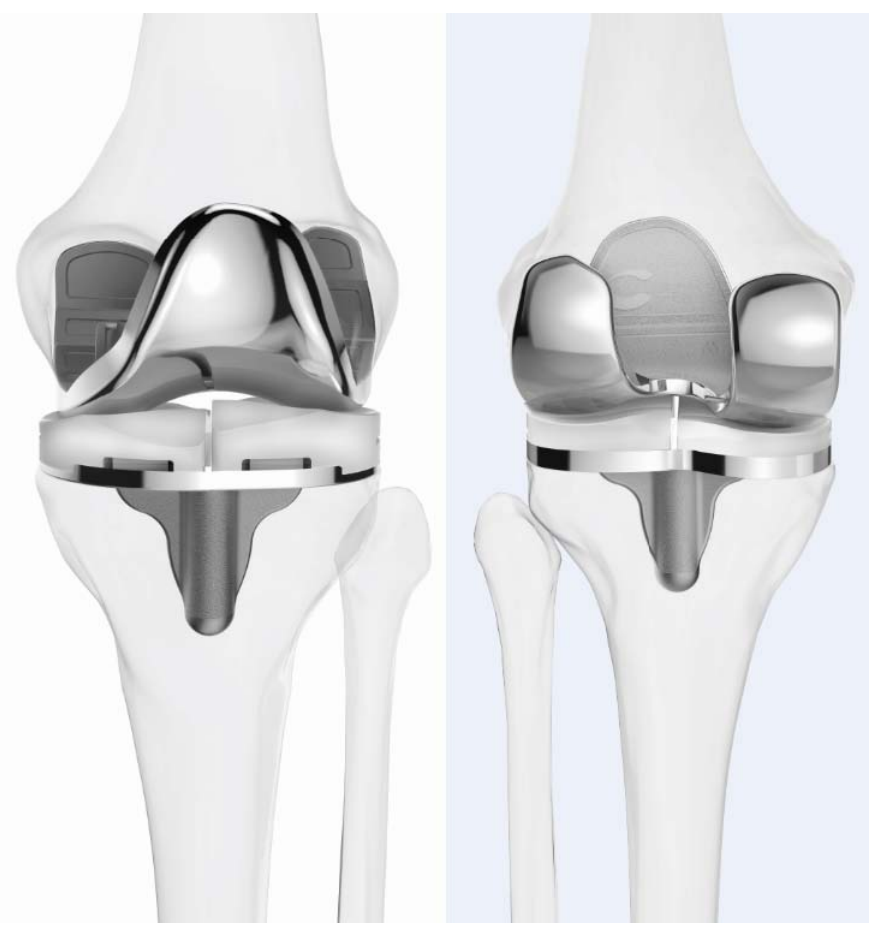

Figure 2. The patient-specific iTotal implant.

The tibial plateau system is also patient-specific, though there is less opportunity to preserve bone stock on the tibial plateau side. This is primarily due to the strength requirements for the metal base plate and a minimum polyethylene thickness requirement of $6 \mathrm{~mm}$. The shape of the tibial base plate is derived from the patient's natural geometry at the level of the planned tibial resection. The tray profile is $1.5 \mathrm{~mm}$ smaller than the planned tibial cut to allow for minor rotational adjustments of the implant at the time of surgery. Separate medial and lateral inserts are provided, creating the opportunity to balance each compartment individually and correct any potential coronal leg malalignment. The articular geometry is derived from the femoral component. The medial insert geometry is slightly more conforming than the lateral insert. The coronal geometry utilizes a broad radius on both condyles, thus employing the round on round principle that has been shown to reduce contact stress. The coronal conformity is extremely high, yet yields a relatively low constraint design, bridging the best of both worlds. The coronal center to center of the condyles is individualized based on the patient's natural dimension. This individualization of the condyle center to center allows the contact geometry to be optimized for each patient and thus not suffer from compromises that 'off the shelf' implant have.

\section{Methods}

In order to determine the amount of bone preservation the iTotal femoral component can yield when compared to conventional TKR, two different approaches were taken, ultimately producing a similar result. The first approach used real world data to conduct a comparative analysis of actual bone cuts made during implantation of both iTotal and competitive systems. The second approach used CAD software to prepare the patient for implantation and the prescribed resections were recorded.

\section{Intraoperative Bone Resection Method}

Between June of 2011 to January of 2013, the thickness of bone removed from the distal medial femoral condyle, distal lateral femoral condyle, posterior medial femoral condyle, posterior lateral femoral condyle, the medial tibial plateau, and the lateral tibial plateau were recorded for every knee replacement performed by one surgeon. The combined thickness of the medial extension gaps was recorded by placing the distal medial femoral condyle on top of the medial tibial plateau and measuring the combined thickness of the two pieces of bone together as described by Hodge [5]. The thickness of the lateral extension gap, and the medial and lateral flexion gap were recorded in the same fashion. This data collection was part of an IRB approved study looking at bone resection and range of motion. The implant selection included 37 Zimmer posterior stabilized NexGen high flex TKRs, 32 Zimmer cruciate retaining NexGen high flex TKAs, and 100 ConforMIS cruciate retaining ITotal TKAs. The saw blade thickness was included in the reported bone measurements.

\section{Virtual Bone Resection Method}

The second approach involved a virtual CAD simulation comparing standard off the shelf knee designs to a patient-specific implant system of a similar size. 15 CT scans were utilized from the ConforMIS database that had undergone the design process for the iTotal cruciate retaining knee system. The CT scan contains detailed data for the femoral head, $60 \mathrm{~mm}$ of the knee joint, and the center of the ankle. The $\mathrm{CT}$ scans are converted to a point cloud for the hip, knee, and ankle and then converted into a CAD models. The CAD models were divided into three size groups. A knee with a femoral A-P length between $53 \& 56 \mathrm{~mm}$ was considered a small size, a knee with a femoral A-P length between $61 \& 63 \mathrm{~mm}$ was a medium size, and a knee 
with a femoral A-P length between $74 \& 76 \mathrm{~mm}$ was considered a large size. The CT scans were selected so that there were 5 knees falling into each size group.

Radiographic sizing templates were obtained for 5 contemporary total knee systems that are in widespread use today. The radiographic templates include the Zimmer NexGen, the J\&J DePuy Sigma, the Smith \& Nephew Legion, the Smith \& Nephew Journey, and the Stryker Triathlon implants.

The sagittal view of the radiographic template was traced using CAD software and the image was then scaled down to represent a $100 \%$ sized profile based on the scale factor provided on the radiographic template. The process was repeated on each size radiographic template. Verification that the scaling was accurate was determined by comparing the advertised anterior to posterior dimension of the particular implant to the generated image. All dimensions were confirmed to within $0.1 \mathrm{~mm}$.

The 15 CAD knee models were then processed through the proprietary design software that generates a patientspecific total knee femoral component, which has all of the bone cuts placed for optimal bone preservation; thus, every femoral component is different. A component of the design process includes resection of the bone model where the implant will be placed.

Once the patient-matched implant was designed, the implant and bone model were converted back into a CAD program to conduct the volumetric analysis. The bone resection for each patient-matched implant was then measured utilizing the volume function within the CAD program. The volume for each knee model was then recorded for the patientspecific implant. Figure 3 shows a typical CAD image of the bone resection removed from the bone model. The volume analysis CAD tool was used to determine

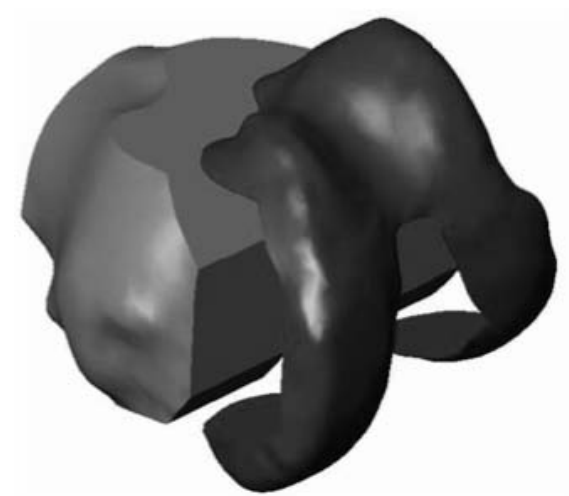

Figure 3. Showing the bone resection removed during the $C A D$ bone removal process. the volume of bone removed.

We then used a copy of the same CAD bone model that was used to produce the patient-specific knee component to conduct an analysis of the off-the-shelf knee components. Since the radiographic templates are 2-dimensional images, this analysis was conducted in the sagittal plane. Using the established size ranges and standard orthopedic guidelines, the competitive implants were best fit to the bone model. When choosing the correct location and size for competitive implants, the following rules were established for repeatability and to ensure simulation of proper placement was consistently established:

1. The posterior condylar surface of the competitive template aligns to the posterior surface of the bone.

2. No anterior notching of the femoral cortex occurs.

3 . The anterior to posterior dimension of the radiographic image should be within $2 \mathrm{~mm}$ of the bone model in the sagittal view.

4. The distal medial condylar surface of the competitive template image aligns to the distal surface of the bone.

When the best size and placement of the competitive implant was determined, the surfaces of the 2-dimensional implant overlay were used to remove the bone virtually from the bone model. This was repeated for each competitive implant using the volume tool to record the required resection value for each virtual surgery.

\section{Results}

\section{Results of Intraoperative Resection Analysis}

The results for the intraoperative bone resection method are tabulated in Tables 1,2 and 3 below. Table 1 provides the results for the calculated average bone resections for all cases in the intraoperative bone resection method. Pvalues were determined using a two tailed student $t$-test. In all cases, the ConforMIS iTotal showed statistically significant less bone resection compared to both Zimmer NexGen products.

Table 2 provides the implant thicknesses for all of the implants used in the intraoperative bone resection method. The thickness for the Zimmer implants was obtained from technical literature provided by the manufacturer. The ConforMIS iTotal thickness was obtained from a pre-surgical planning guide provided by the manufacturer. With the exception of the lateral tibial thickness for the ConforMIS iTotal, all other implant thickness was greater for the Zimmer NeGen implants.

The amount of bone resected from the posterior medial femoral condyle more closely matched the amount of bone resected from lateral femoral condyles with the iTotal, as shown in Table 3. The lower values in the ConforMIS knees indicate that the femoral components in the iTotal knees more closely matched the femoral curvature, which is possible with the iTotal due to the differing heights of the medial and lateral polyethylene, along with the inbuilt distal and posterior femoral off-sets. 
Table 1: Average Thickness of Bone Resection in $\mathrm{mm}$

\begin{tabular}{|c|c|c|c|c|c|c|c|c|c|c|c|}
\hline Implant & $\begin{array}{c}\text { \# OF } \\
\text { CASES }\end{array}$ & $\begin{array}{c}\text { DISTAL } \\
\text { MEDIAL } \\
\text { FEMORAL } \\
\text { RESECTION } \\
\end{array}$ & $\begin{array}{c}\text { DISTAL } \\
\text { LATERAL } \\
\text { FEMUR } \\
\text { RESECTION } \\
\end{array}$ & $\begin{array}{c}\text { POSTERIOR } \\
\text { MEDIAL } \\
\text { FEMORAL } \\
\text { RESECTION }\end{array}$ & $\begin{array}{c}\text { POSTERIOR } \\
\text { LATERAL } \\
\text { FEMORAL } \\
\text { RESECTION }\end{array}$ & $\begin{array}{c}\text { MEDIAL } \\
\text { TIBIAL } \\
\text { RESECTION }\end{array}$ & $\begin{array}{c}\text { LATERAL } \\
\text { TIBIAL } \\
\text { RESECTION }\end{array}$ & $\begin{array}{c}\text { Medial } \\
\text { Extension } \\
\text { Gap } \\
\text { Resection }\end{array}$ & $\begin{array}{c}\text { Lateral } \\
\text { Extension } \\
\text { Gap } \\
\text { Resection }\end{array}$ & $\begin{array}{c}\text { Medial } \\
\text { Flexion } \\
\text { Gap } \\
\text { Resection }\end{array}$ & $\begin{array}{c}\text { Lateral } \\
\text { Flexion } \\
\text { Gap } \\
\text { Resection }\end{array}$ \\
\hline Zimmer PS & 37 & 7.76 & 7.37 & 10.58 & 8.24 & 6.13 & 9.47 & 14.53 & 17.08 & 17.03 & 17.89 \\
\hline Zimmer CR & 32 & 7.79 & 7.88 & 11.36 & 9.36 & 6.64 & 8.64 & 14.82 & 16.30 & 17.73 & 17.70 \\
\hline \multicolumn{12}{|c|}{ Difference between Zimmer and Conformis } \\
\hline \multicolumn{2}{|c|}{ Zimmer - Conformis in mm } & 1.35 & 1.21 & 3.95 & 2.89 & 3.33 & 1.68 & 4.88 & 3.43 & 7.18 & 5.14 \\
\hline \multicolumn{2}{|c|}{ Zimmer - Conformis in \% } & $17.4 \%$ & $15.9 \%$ & $36.1 \%$ & $33.0 \%$ & $52.4 \%$ & $18.5 \%$ & $33.3 \%$ & $20.5 \%$ & $41.4 \%$ & $28.9 \%$ \\
\hline \multicolumn{2}{|c|}{ Zimmer - Conformis p value } & $\mathrm{P}<0.0001$ & $\mathrm{P}<0.0001$ & $\mathrm{P}<0.0001$ & $P<0.0001$ & $\mathrm{P}<0.0001$ & $\mathrm{P}<0.0001$ & $\mathrm{P}<0.0001$ & $\mathrm{P}<0.0001$ & $\mathrm{P}<0.0001$ & $\mathrm{P}<0.0001$ \\
\hline
\end{tabular}

Table 2: Average Implant thickness in $\mathrm{mm}$

\begin{tabular}{|c|c|c|c|c|c|c|}
\hline Implant & $\begin{array}{c}\text { DISTAL MEDIAL } \\
\text { FEMORAL } \\
\text { THICKNESS }\end{array}$ & $\begin{array}{c}\text { DISTAL } \\
\text { LATERAL } \\
\text { FEMUR } \\
\text { THICKNESS }\end{array}$ & $\begin{array}{c}\text { POSTERIOR } \\
\text { MEDIAL } \\
\text { FEMORAL } \\
\text { THICKNESS }\end{array}$ & $\begin{array}{c}\text { POSTERIOR } \\
\text { LATERAL } \\
\text { FEMORAL } \\
\text { THICKNESS }\end{array}$ & $\begin{array}{l}\text { MEDIAL TIBIAL } \\
\text { THICKNESS }\end{array}$ & $\begin{array}{c}\text { LATERAL } \\
\text { TIBIAL } \\
\text { THICKNESS }\end{array}$ \\
\hline Zimmer PS & 10 & 10 & 12 & 12 & 10.44 & 10.44 \\
\hline Zimmer CR & 9 & 9 & 11 & 11 & 10.21 & 10.21 \\
\hline Zimmer - Conformis in mm & 1.60 & 1.76 & 5.14 & 5.27 & 1.91 & -0.37 \\
\hline Zimmer - Conformis in \% & $16.8 \%$ & $18.4 \%$ & $44.6 \%$ & $45.7 \%$ & $18.5 \%$ & $-3.6 \%$ \\
\hline Zimmer - Conformis p value & $P<0.0001$ & $P<0.0001$ & $P<0.0001$ & $P<0.0001$ & $P<0.0001$ & $\mathrm{P}=0.227$ \\
\hline
\end{tabular}

Table 3: Difference in Posterior Femoral Resection in $\mathrm{mm}$

\begin{tabular}{|c|c|c|}
\hline & Posterior Medial femur - Posterior Lateral femur Resection & P value compared to Conformis \\
\hline Zimmer PS & 2.34 & $(\mathrm{p}=0.006)$ \\
\hline Zimmer CR & 2.00 & $(\mathrm{p}=0.044)$ \\
\hline Conformis CR & 1.13 & \\
\hline
\end{tabular}

\section{Results of Virtual Analysis}

The tabulated results are reported in $\mathrm{mm} 3$. The size reported is the size of the competitive implant as defined by each manufacturer. The iTotal size is described by the serial number since each implant is unique and patient-specific. The data is tabulated and referenced by a serial number, which is a unique identifier for each original CT scan. Each serial number scan has bone resection data for the iTotal femoral component as well as the resection data for each of the competitive off-the-shelf femoral components from Zimmer, Smith \& Nephew, DePuy, and Stryker.

Results for all measurements are tabulated in Table 4.

The average bone resection increase for all tested competitive implants compared to the iTotal, regardless of size, is $28 \%$.

For the small sized implant group, the sampled iTotal implants required less bone resection volumetrically compared to the 5 implant systems tested. The average bone resection increase for the competitive implants was $49 \%$. The increase in bone resection ranged from $30 \%$ to $77 \%$.

For the medium sized implant group, the sampled iTotal implants required less bone resection volumetrically compared to the 5 implant systems tested. The average bone resection increase for the competitive implants was $25 \%$. The increase in bone resection ranged from $11 \%$ to $46 \%$.

For the large sized implant group, the sampled iTotal implants required less bone resection volumetrically compared to the 5 implant systems tested. The average bone resection increase for the competitive implants was $12 \%$. The increase in bone resection ranged from $7 \%$ to $18 \%$.

\section{Discussion}

We hypothesized that a patient-specific implant would preserve more bone as compared to a standard off-the- 
Table 4: Comparison of resected bone thicknesses obtained during CAD analysis. (mm)

\begin{tabular}{|c|c|c|c|c|c|c|}
\hline \multicolumn{7}{|c|}{ Small Size } \\
\hline & Size & A-P Length & $\begin{array}{l}\text { Distal Medial } \\
\text { Thickness }\end{array}$ & $\begin{array}{c}\text { Distal Lateral } \\
\text { Thickness }\end{array}$ & $\begin{array}{c}\text { Posterior } \\
\text { Medial } \\
\text { Thickness }\end{array}$ & $\begin{array}{c}\text { Posterior } \\
\text { Lateral } \\
\text { Thickness }\end{array}$ \\
\hline Zimmer NexGen & $\mathrm{C}$ & 54 & 9 & 9 & 9 & 9 \\
\hline Johnson \& Johnson PFC Sigma & 1.5 & 53 & 9 & 9 & 8 & 8 \\
\hline Smith \& Nephew Legion & 3 & 54.5 & 9.4 & 9.4 & 9.3 & 9.3 \\
\hline Stryker Triathlon PS & 1 & 53 & 8.5 & 8.5 & 8.2 & 8.2 \\
\hline Smith \& Nephew Journey & 2 & 53 & 7.5 & 5.3 & 7.5 & 5.6 \\
\hline Average for Standard Sample & - & 53.5 & 8.7 & 8.2 & 8.4 & 8.0 \\
\hline ConforMIS: Serial \#10768 & - & 55 & 6.0 & 6.0 & 6.3 & 6.6 \\
\hline ConforMIS: Serial \#3017 & - & 55 & 6.6 & 6.6 & 5.0 & 5.2 \\
\hline ConforMIS: Serial \#12601 & - & 56 & 7.0 & 7.0 & 6.5 & 5.6 \\
\hline Average for ConforMIS Sample & - & 55.3 & 6.5 & 6.5 & 5.9 & 5.8 \\
\hline Delta (Standard vs. ConforMIS) & & & -2.2 & -1.7 & -2.5 & -2.2 \\
\hline \multicolumn{7}{|c|}{ Medium Size } \\
\hline & Size & A-P Length & $\begin{array}{c}\text { Distal Medial } \\
\text { Thickness }\end{array}$ & $\begin{array}{c}\text { Distal Lateral } \\
\text { Thickness }\end{array}$ & $\begin{array}{c}\text { Posterior } \\
\text { Medial } \\
\text { Thickness }\end{array}$ & $\begin{array}{c}\text { Posterior } \\
\text { Lateral } \\
\text { Thickness }\end{array}$ \\
\hline Zimmer NexGen & $\mathrm{E}$ & 62 & 9 & 9 & 9.3 & 9.3 \\
\hline Johnson \& Johnson PFC Sigma & 3 & 61 & 9 & 9 & 8 & 8 \\
\hline Smith \& Nephew Legion & 5 & 62 & 9.5 & 9.5 & 9.3 & 9.3 \\
\hline Stryker Triathlon PS & 4 & 62 & 8.5 & 8.5 & 8.5 & 8.5 \\
\hline Smith \& Nephew Journey & 5 & 62 & 9.5 & 7.0 & 9.5 & 7.4 \\
\hline Average for Standard Sample & - & 61.8 & 9.1 & 8.6 & 8.9 & 8.5 \\
\hline ConforMIS: Serial \#10535 & - & 62 & 6.3 & 6.9 & 5.9 & 5.7 \\
\hline ConforMIS: Serial \#11399 & - & 62 & 6.9 & 7.7 & 5.9 & 5.6 \\
\hline ConforMIS: Serial \#11675 & - & 62 & 7.5 & 5.9 & 5.5 & 6.1 \\
\hline Average for ConforMIS Sample & - & 62 & 6.9 & 6.8 & 5.8 & 5.8 \\
\hline Delta (Standard vs. ConforMIS) & & & -2.2 & -1.8 & -3.1 & -2.7 \\
\hline \multicolumn{7}{|c|}{ Large Size } \\
\hline & Size & A-P Length & $\begin{array}{l}\text { Distal Medial } \\
\text { Thickness }\end{array}$ & $\begin{array}{c}\text { Distal Lateral } \\
\text { Thickness }\end{array}$ & $\begin{array}{c}\text { Posterior } \\
\text { Medial } \\
\text { Thickness }\end{array}$ & $\begin{array}{c}\text { Posterior } \\
\text { Lateral } \\
\text { Thickness }\end{array}$ \\
\hline Zimmer NexGen & $\mathrm{H}$ & 76 & 9 & 9 & 9 & 9 \\
\hline Johnson \& Johnson PFC Sigma & 6 & 74 & 10 & 10 & 9 & 9 \\
\hline Smith \& Nephew Legion & 8 & 75 & 9.5 & 9.5 & 11.3 & 11.3 \\
\hline Stryker Triathlon PS & 8 & 75 & 8.5 & 8.5 & 8.6 & 8.6 \\
\hline Smith \& Nephew Journey & 9 & 75 & 11.5 & 9.0 & 11.5 & 9.4 \\
\hline Average for Standard Sample & - & 75 & 9.7 & 9.2 & 9.9 & 9.5 \\
\hline ConforMIS - Serial \#7837 & - & 75 & 7.9 & 7.6 & 7.0 & 6.9 \\
\hline ConforMIS: Serial \#11863 & - & 75 & 6.7 & 8.9 & 7.6 & 6.3 \\
\hline ConforMIS: Serial \#12108 & - & 74 & 8.1 & 8.0 & 7.2 & 6.6 \\
\hline Average for ConforMIS Sample & - & 74.7 & 7.6 & 8.2 & 7.3 & 6.6 \\
\hline Delta (Standard vs ConforMIS) & & & -2.1 & -1.0 & -2.6 & -2.9 \\
\hline
\end{tabular}


shelf design, which we tested in actual practice through a measured resection technique. We then further tested this hypothesis volumetrically with a virtual application utilizing CAD imaging. Both methods of testing bone resection yielded similar results demonstrating that the patientspecific design preserved a significantly greater amount of bone during implantation.

There are limitations to this study. In the actual resection group, measurements include remaining cartilage, which is variable in each patient dependent on disease status. Given that these are all patients with significant disease requiring TKA and that the measurement methodology was consistent, the effect across groups is believed to be minimal. In the virtual resection group, access to actual CAD models of the standard implants would be the most precise method to measure volumetric bone resection. However, obtaining CAD models of these implants is not possible as all of the manufacturers consider this information proprietary. Utilizing the radiographic templates provided the most accurate secondary method.

The bone preserving aspect of the ConforMIS iTotal can be explained by four unique design features:

1. Each bone cut is individualized for each patient, meaning every single femoral cut is moved to the most peripheral location possible for a patient's unique geometry.

2. The 6 th facet of the femoral component affords more peripheral resection and a stronger implant design, which in turn enables a thinner femoral component.

3. A stepped distal femoral cut preserves bone on the medial femoral condyle.

4. The restoration of the patient's own 'J' curve seems to allow the surgeon to resect less bone and still balance the knee joint accordingly.

Comparing the implant thickness of the ConforMIS iTotal to the high flex Zimmer Nexgen, the Zimmer implant demonstrates a substantially thicker posterior femoral implant in the high flex implant and, subsequently, a thicker posterior femoral bone resection.

The iTotal preserves more of the medial tibial plateau bone based on a tibial resection that is $2 \mathrm{~mm}$ below the medial subcondural surface. The intraoperative bone resection method data shows that the ConforMIS iTotal has a slightly thicker lateral tibial implant thickness compared to the Zimmer NexGen. This is caused by the anatomically thicker lateral insert of the iTotal system that is dictated by preservation of the patient's natural ' $\mathrm{J}$ ' curves and natural offset between the medial and the lateral femoral condyle of the patient. The iTotal femoral component relies on the elevated lateral polyethylene to tighten up the lateral flexion gap instead of externally rotating the femoral compo- nent as is often required in standard implants. This allows the femoral component to be better situated along the epicondylar axis.

\section{Conclusions}

The ConforMIS iTotal patient-specific implants preserve significantly more bone than standard total knee replacements due to both the thickness of the required bone resections as well as the implant thickness being tailored to each patient's individual knee. This will translate to having more native bone available in the event that a patient requires a revision. The hope is that this patient-specific approach may enable revision to a standard primary total knee in the future rather than a revision implant. Alternately, in the event extensive osteolysis has developed, a patient-specific primary implantation may at least obviate the need for spacer and augments when the time comes for revision surgery.

The amount of bone resected from the posterior medial femoral condyle more closely matched the amount of bone resected from lateral femoral condyles with the iTotal as shown in Table 3. The lower values in the ConforMIS knees indicate that the femoral components in the iTotal knees more closely matched the femoral curvature, which is possible with the iTotal due to the differing heights of the medial and lateral polyethylene.

\section{Disclosure}

One or more of our authors have disclosed information that may present potential for conflict of interest with this work. For full disclosures refer to last page of this journal.

\section{References}

1. S. Kurtz, K. Ong, E. Lau, F. Mowat, M. Halpern, Projections of primary and revision hip and knee arthroplasty in the United States from 2005 to 2030, J. Bone Joint Surg. Am. 89 (2007) 780-785.

2. M.A. Mont, T.M. Seyler, P.S. Ragland, R. Starr, J. Erhart, A. Bhave, Gait analysis of patients with resurfacing hip arthroplasty compared with hip osteoarthritis and standard total hip arthroplasty, J Arthroplasty 22 (2007) 100-108

3. D.L. Bartel, V.L. Bicknell, T.M. Wright, The effect of conformity, thickness, and material on stresses in ultra-high molecular weight components for total joint replacement, J. Bone Joint Surg. Am. 68 (1986) 1041-1051

4. R.A. Bojarski, R. Ketelholn, B.S. Parsley, J.E. Slamin, Optimizing knee femoral component strength and bone preservation with finite element analysis, 58th Annual Meeting of the Orthopedic Research Society (2012) Poster No. 1042

5. W.A. Hodge, Intraoperative assessment of bone cuts to guide surgical technique during total knee arthroplasty, J. Bone Joint Surg. Am. 89 (2007) 137-43 